Revue d'histoire de l'Amérique française

REYUE D.HISTOIRE DE L'AMÉRIQUE FRANÇAISE

\title{
COMMUNAUTÉ URBAINE DE MONTRÉAL, Les édifices publics. Répertoire d'architecture traditionnelle sur le territoire de la communauté urbaine de Montréal, 1981. 323 p. \$5.00.
}

\section{Robert Lahaise}

Volume 36, numéro 3, décembre 1982

URI : https://id.erudit.org/iderudit/304084ar

DOI : https://doi.org/10.7202/304084ar

Aller au sommaire du numéro

Éditeur(s)

Institut d'histoire de l'Amérique française

ISSN

0035-2357 (imprimé)

1492-1383 (numérique)

Découvrir la revue

Citer ce compte rendu

Lahaise, R. (1982). Compte rendu de [COMMUNAUTÉ URBAINE DE MONTRÉAL, Les édifices publics. Répertoire d'architecture traditionnelle sur le territoire de la communauté urbaine de Montréal, 1981. 323 p. \$5.00.] Revue d'histoire de l'Amérique française, 36(3), 448-448. https://doi.org/10.7202/304084ar d'utilisation que vous pouvez consulter en ligne. 
COMMUNAUTÉ URBAINE DE MONTRÉAL. Les édifices publics. Répertoire d'architecture traditionnelle sur le territoire de la communauté urbaine de Montréal, 1981. 323 p. $\$ 5.00$

Poursuivant son projet de nous fournir en douze volumes un répertoire le plus exhaustif possible «de l'architecture traditionnelle sur son territoire», le Service de la planification de la Communauté urbaine de Montréal nous offre ici son premier tome en architecture civile - le deuxième, déjà paru, était consacré aux édifices scolaires - relatif aux édifices publics. On y retrouve donc un inventaire de nos divers bains, bibliothèques, bureaux de poste, gares, hôpitaux, hôtels de ville, marchés, palais de justice, postes d'incendie, etc., depuis 1832 jusqu'à 1937. Le choix de ce siècle semblait s'imposer, d'une part, par la disparition des édifices publics antérieurs, et d'autre part, par l'avènement de l'architecture contemporaine au cours de la deuxième guerre mondiale.

Il y a quelque 125 ans, Québec et Montréal se retrouvaient en chantier. De traditionnellement françaises qu'elles avaient été jusqu'alors, commerce et industrie britanniques démantelaient leurs centre-villes. Faucher de Saint-Maurice constatait d'ailleurs qu'en une décennie, la capitale avait subi plus de démolitions qu'elle n'en avait connues depuis la Guerre de la Défaite!

De toute façon, dès 1825 , un étrange mariage romanticomercantile accouchait d'un nostalgique néo-gothique - notre somptuaire église Notre-Dame - fraternisant avec le néo-classique. De ce dernier style, notre vieux Palais de Justice et le Marché Bonsecours sont les meilleurs exemples, avec leurs dômes «romains» et leurs vastes porches à colonnades.

Suit alors le triomphalisme victorien: nouveau centre ferroviaire, Montréal l'incarne tout particulièrement par ses gares Viger et Windsor. Le tout se termine enfin, en ce début du $\mathrm{XX}^{\mathrm{e}}$ siècle, par un nouveau flirt avec la culture française, son art-déco et son École d'architecture. Avec cette ère Beaux-Arts, empreinte d'une certaine sobriété parfois massive - Musée des Beaux-Arts, Bibliothèque municipale - parfois élégamment aristocratique - Bain Maisonneuve, Bibliothèque Saint-Sulpice se clôt cet intéressant survol signé G.C.

Je me demande d'ailleurs pourquoi tous les hauts fonctionnaires signent, sauf l'auteur..., tout comme je ne comprends guère le pourquoi de la page 323, qui nous fournit la provenance de neuf photographies, sans préciser celle des quelque deux cents autres. Je m'interroge enfin sur la pertinence de la division "en 12 sections thématiques»: pour s'y retrouver, n'aurait-il pas été plus simple de présenter les édifices par ordre alphabétique? Comment deviner, entre autres, que les couvents ne sont pas avec les édifices scolaires? 